\title{
घ : Olhares sobre a cidade: humor e crônica urbana
}

\section{Carlos Bonfim}

Professor de Lingua e Literaturas Espanhola e Hispano-americana da Faculdade de Letras da Universidade Federal de Alagoas (Ufal).

Resumo: Este artigo apresenta uma síntese de minha pesquisa sobre cultura e comunicaçāo urbana, realizada junto à Universidad Andina Simón Bolívar, no Equador e publicada originalmente no livro Humor y crónica urbana: ciudades vividas, ciudades imaginadas. Nesta pesquisa realizei uma leitura que cruzava crônicas urbanas, estudos sobre a cidade e humor, cujo propósito era refletir sobre os sentidos de uso da cidade; refletir sobre como conceben os cronistas a cidade do ponto de vista do uso dos espaços urbanos e da interação entre os cidadãos.

Palavras-chave: crônica; humor; riso; cidade
Resumen: Este artículo presenta una sintesis de mi investigación sobre cultura y comunicación urbana, realizada junto a la Universidad Andina Simón Bolívar, en Ecuador y publicada originalmente en el libro Humor y crónica urbana: ciudades vividas, ciudades imaginadas. En esta investigación realicé una lectura que cruzaba crónicas urbanas, estudios sobre la ciudad y humor, cuyo propósito era reflexionar sobre los sentidos de uso de la ciudad, reflexionar sobre como conciben los cronistas la ciudad desde el punto de vista del uso de los espacios urbanos y de interacción entre los ciudadanos.

Palabras-llave: crónica; humor; risa;ciudad 



\section{Caminhos de uma pesquisa e roteiro de leitura}

Um esclarecimento inicial: o que se lerá neste artigo é uma breve síntese da pesquisa que realizei durante o mestrado em Letras na Universidad Andina Simón Bolívar, sede Quito, e que foi publicada em 2003 com o título de Humor y crónica urbana: ciudades vividas, ciudades imaginadas.

Um segundo esclarecimento diz respeito ao projeto em que se insere esta pesquisa sobre as crônicas. Meu propósito, a longo prazo, é realizar uma série de pesquisas sobre a função social do riso. Ou seja, partindo de uma definição do riso como uma estratégia discursiva, como uma forma - que considero privilegiada - de intervir nos assuntos da vida diária, interessa-me estudar não os mecanismos de produção do cômico, mas sobretudo sua incidência na vida cotidiana. Desse modo, este trabalho com as crônicas é um primeiro recorte de um projeto que pretende refletir sobre o riso nas mais diversas dimensões de nossas práticas cotidianas e de nossa produção cultural. O segundo módulo desta pesquisa debruça-se - com os mesmos objetivos - sobre as relações entre música e humor.

Apresento aqui uma breve introdução sobre o que entendo como função social do riso, identifico seu caráter aglutinador e propositivo e apresento algumas reflexões a partir do recurso ao humor identificado num conjunto de crônicas produzidas por diversos autores latino-americanos ${ }^{1}$. O fio condutor na seleção dos textos foi, por um lado, o riso e o humor que caracterizam os textos dos autores selecionados. Por outro lado, a seleção teve o propósito de refletir, fundamentalmente, sobre os sentidos de uso da cidade; ou seja, sobre como concebem os cronistas a cidade do ponto de vista do uso dos espaços urbanos, da interação entre ui sidadãos. Se o olhar do cronista é, como proponho, um olhar crítico, um olhar que, a partir das crônicas, nos revela o que estamos sendo, a crônica pode ser definida, tal como se verá a seguir, como um espelho de nossas atuações urbanas.
${ }^{1}$ Os autores sobre os quais foi realizada a pesquisa são: Carlos Drummond de Andrade, Luis Fernando Veríssimo e Sérgio Porto (Brasil), Eduardo Galeano (Uruguai), Jorge Ibarguengoitia (México), Roberto Arlt e Antonio Dal Masetto (Argentina), Daniel Samper Pizano (Colombia), Carlos Andrade e Francisco Febres Cordero (Equador). 


\section{Olhar de cima, olhar de baixo: olhares}

Cheguei ao nome da cidade Não à cidade mesma, espessa

Caetano Veloso

De onde falo quando falo da cidade? Onde pousam meus olhos quando construo sobre a cidade os meus relatos cotidianos? Como vivo, como uso e... como imagino a cidade que habito?

Olhares de cima, de longe, de fora, de dentro, de perto... Pontos de vista. Perspectivas determinadas pelo lugar onde se está, perspectivas definidas pelo uso cotidiano que fazemos do espaço urbano. Um espaço que, segundo observam Jesús Martín-Barbero (1998), Armando Silva (1997) e Carlos Monsiváis (1997), experimentou violentas reconfigurações nos modos de estar juntos e de perceber a cidade e seus cidadãos.

Dado que uma cidade não se define apenas pelo seu aspecto topográfico (natural ou edificado), mas também pelo uso e pelas representações que dela fazem os seus habitantes, entender a cidade requer considerar que a vida urbana é uma trama complexa que precisa ser estudada tanto a partir de sua dimensão física, quanto de sua dimensão social, subjetiva. Deste modo, além dos geógrafos, arquitetos, engenheiros e urbanistas, entre os novos "cartógrafos" da cidade estão os artistas: seres urbanos cujo ofício consiste em caminhar pela cidade e recolher nas ruas as histórias à margem da imagem - para parafrasear o título de um recente documentário sobre os habitantes das ruas. $E$ entre esses artistas, nos detemos sobre o ofício do cronista. Mas a partir de que perspectiva narrar a cidade? A partir da cidade olhada de cima, do panóptico, da janela mais alta da Secretaria de Planejamento Urbano do Município? Ou a partir da cidade usada, vivida pelo transeunte anônimo, e cotidiano, de ruas, calçadas, praças, etc?

Ora, se "ver, cheirar, ouvir, passear, deter-se, recordar, representar são atributos que devem ser estudados em cada cidade" (SILVA, 1997, p. 24), o cronista se oferece 
como um aliado fecundo para tais reflexões. E aceitamos, então, o convite feito por Michel de Certeau (1996) e, em lugar da visão panorâmica, em lugar do olho totalizador, optamos pelo "olhar de baixo", pelo olhar ao rés-do-chão. A ele, pois.

\section{Humor e crônica: o sentir em comum}

Uma revisão dos estudos de M. Bakhtin, S. Freud. H. Bergson, U. Eco, L.Pirandello e G.Minois, permite identificar que entre as funções sociais mais significativas do riso está a de proporcionar prazer - desde que não sejamos nós o objeto do riso, claro. Em seu estudo sobre o cômico, por exemplo, Freud trata de identificar a psicogênese do cômico e como se constituem os mecanismos do prazer. Freud aborda os processos psíquicos que se verificam nos sujeitos expostos ao cômico, os meios técnicos do cômico, seus motivos e seu papel no imaginário social.

Rir, constata-se, nos proporciona prazer. Mas de que rimos? O que nos faz rir? Rimos do disparatado, rimos pelo reconhecimento e, conforme o caso, pela comparação. Rimos daquilo que é excessivo ou desapropriado: o exagero característico da pantomima e do clowncontrasta com nossos gestos cotidianos. Rimos das deformações: a elas opomos o que consideramos normal. A caricatura, uma das formas privilegiadas da deformidade, faz rir destacando / degradando determinados traços isolados que resultam cômicos. Ainda no âmbito da comparação, são cômicos, ou deles se extrai a comicidade, o pertencimento étnico e social, os diferentes sotaques, sexos, raças, nacionalidades. O cômico funciona a partir do reconhecimento do referente: para que se efetive, a comicidade depende tanto de um contexto cultural quanto temporal. O cômico faz rir apenas se reconhecemos as circunstâncias e o contexto em que ocorre.

Identifico nestas reflexões sobre a função social do riso um duplo movimento: por um lado, adverte-se (no riso) um movimento que visa à exposição de fissuras sociais, do ridículo, mas com um afã - ainda que implícito propositivo. Neste caso, estaríamos falando de um papel 
2 "Um leitor de periódicos - conclui Anderson - que observa réplicas exatas consumidas por seus vizinhos no metrô, na barbearia ou na vizinhança, confirma continuamente que o mundo está visivelmente arraigado na vida diária."

(ANDERSON, 1993, p.60-61). dessacralizador do riso. Por outro lado, adverte-se um riso estigmatizador, que, através de preconceitos e estereótipos, opera fundamentalmente com uma abordagem preconceituosa das diferenças. Em ambos os casos identifico no riso uma função coesiva. Reconheço um olhar coletivo, um olhar que instaura um grupo, que faz com que o indivíduo experimente essa sensação de pertencer a uma determinada comunidade. Daí ser possível afirmar que humor e crônica aglutinam um determinado grupo social ao redor de um sentimento experimentado em comum. Nosso riso, ensina Bergson, é sempre o riso de um grupo:

não saborearíamos o cômico se nos sentíssemos isolados. [...] Por mais espontâneo que se creia, [o riso] sempre oculta um pré-conceito de associação e de cumplicidade entre outros "rintes" efetivos ou imaginários". (BERGSON, 1991, p. 14)

Pensar o riso em termos de participação numa comunidade nos remete à noção de comunidade imaginada proposta por Anderson, segundo a qual

os membros de uma nação, por menor que seja, não conhecerão jamais a maioria de seus compatriotas, não os verão nem ouvirão jamais falar deles, mas na mente de cada um vive a imagem de sua comunhão. (ANDERSON, 1993, p. 23)

Participamos física e imaginariamente de uma COmunidade. Fisicamente ao compartilhar espaços concretos, tangíveis, nos quais desenvolvemos as diferentes atividades da vida cotidiana. Imaginariamente, ao participar daquela espécie de "cerimônia massiva", de que fala Anderson: a leitura do jornal, por exemplo, sendo repetida simultaneamente por milhares de pessoas. ${ }^{2}$ Participar de uma comunidade é, portanto, reconhecer o outro e reconhecer-se como parte de um determinado grupo. Ora, se, como vimos, o cômico só funciona se reconheço o referente, podemos perceber que é precisamente este o aspecto que enlaça humor e crônicas. É precisamente no reconhecimento do contex- 
to, das circunstâncias e do referente que reside uma das principais características das crônicas. O humor presente naqueles textos funciona porque reconhecemos o referente, porque nos reconhecemos muitas vezes naquelas situações. Do mesmo modo que a comédia, a crônica "pinta personagens que já havíamos encontrado em nosso caminho, anota semelhanças, aspira apresentar-nos tipos e, se fosse necessário, os inventaria." (BERGSON, 1991, p. 124). Se, na perspectiva que proponho, o cronista relata nossas práticas cotidianas, as práticas que partilhamos com os habitantes de uma cidade, é possível que nos reconheçamos naqueles textos. Ali estão retratados nossos usos dos espaços públicos, nossos problemas com o vizinho de assento no ônibus, com o caixa do banco, no comércio, etc. Reencontramos nesses textos o conhecido, o que vivemos e praticamos diariamente, aquilo que - precisamente por essa familiaridade cotidiana - não vemos ou não temos a distância crítica necessária para vê-lo. As crônicas se convertem, nesse sentido, em algo como uma sala de espelhos na qual contemplamos imagens caricaturescas. As proporções aparecem exageradas, desproporcionais, deformadas e ridículas, mas nos reconhecemos.

Pois bem, se o humor que caracteriza aquelas crônicas funciona porque reconhecemos o referente, porque nos reconhecemos - os múltiplos e diversos leitores - naquelas situações, poderíamos falar de uma função coesiva do riso. Ler aqueles textos, reconhecer-se, ver-se refletido neles, é também fazer parte de um "nós". É participar, enfim, de uma invenção coletiva que lembra tanto as comunidades imaginadas propostas por Anderson, quanto a noção de imaginários urbanos, proposta por Armando Silva: entendida a cidade como um espaço físico, concreto, mas também como um espaço de dinâmicas culturais, de construções simbólicas, os imaginários urbanos constituem um "relato que completa a percepção real" da cidade. (SILVA, 1997, p. 44). Sobre o espaço construído, produzido, edificado, os cidadãos elaboram representações discursivas, construções simbólicas, imaginadas.

Em sua reflexão sobre a emergência de um "sen- 
${ }^{3}$ A cidade é definida por Barthes, por exemplo, como "uma escritura, como uma inscrição do homem no espaço." (BARTHES, 1993, p.223).

${ }^{4}$ Um texto "cujas palavras se desdobram em rumos diversos e, como todo texto vertiginoso e esquivo, a cidade oferece diferentes possibilidades de leitura.". (VIZCARRA, 1996, p.85). timento coletivo" nas urbes contemporâneas - em diálogo com Anderson e atualizando Max Weber - Michel Maffesoli aponta para a conformação de uma comunidade emocional - cujas características são o "aspecto efêmero, a composição cambiante, a adscrição local, a ausência de organização e a estrutura cotidiana" (MAFFESOLI, 1990, p. 38). Refere-se Maffesoli a uma comunidade de predomínio empático que sente em comum e que se opõe frontalmente a discursos que definem as urbes contemporâneas como espaços privilegiados de um individualismo exacerbado.

Nesse sentido, se insistimos na estrutura cotidiana e na adscrição local características da comunidade emocional, considero pertinente falar da conformação de uma comunidade nas (e a partir das) crônicas. Encontramos ali textos que nos falam não apenas denós - habitantes e usuários da urbe - mas também para nós - que nos reconhecemos como uma comunidade que lê aqueles textos. Lemos nas crônicas nossos embates com a burocracia, nossas inter-relações, nossa participação numa comunidade. Rir ou indignar-se juntos equivale, enfim, a participar de uma emoção coletiva, a participar de uma comunidade que, de acordo com Maffesoli, acaba constituindo uma forma de vínculo social bastante sólida.

É precisamente a partir do cotidiano, do local e da proxemia - âmbitos nos quais se joga o destino comum que a crônica trabalha seus relatos sobre a cidade. Daí a coloquialidade ou a informalidade que se adverte naqueles textos: entre os discursos mercantilizados e tecnologizados dos jornais, a crônica se estrutura como conversa familiar e informal (RAMOS, 1989, p. 131).

\section{O cronista: leitor privilegiado do texto urbano}

Concebida a cidade, a partir das metáforas propostas pela semiologia ${ }^{3}$, como um texto que escrevemos e lemos os transeuntes cotidianos da urbe, defino o cronista como um leitor privilegiado do texto urbano que escrevemos os habitantes da cidade. ${ }^{4}$ 
Semelhante ao flâneur de fins do século XIX, o cronista é um caminhante, um passeante que constrói seus textos a partir dos "textos" (usos, práticas, percursos, experiências, etc) escritos pelos demais cidadãos e por ele mesmo. Mas, tal como propõe Julio Ramos, a "flaneria" "não é simplesmente um modo de experimentar a cidade. É, sobretudo, um modo de representá-la, de olhá-la e contar o visto". (ibidem, p. 128)

E nesse processo de "contar o visto" surgem duas perspectivas possíveis: uma, que funciona como "memória" (ORTEGA, 1999, p. 89) ou como "arquivo" (RAMOS, ibidem, p.113): evoca de modo algo nostálgico uma cidade que já não existe; fala da cidade de antes, da cidade que quase não se reconhece, comparando-a com um tempo pretérito. Outra perspectiva oferece-se como "espelho": propõe um olhar sobre as práticas atuais, falam do que estamos sendo e não do que fomos os cidadãos da urbe. Em ambos os casos, sublinha-se o que define etimologicamente a crônica: sua relação com o tempo. O tempo é a matéria essencial da crônica - daí o fato de que poucas crônicas sobrevivam à conjuntura em que foram publicadas.

Pois bem, narrar a cidade, construir sobre ela um relato, supõe situar nosso olhar numa determinada perspectiva, supõe instaurar um lugar de enunciação; supõe, enfim, estabelecer um ponto de vista. Antônio Candido propõe, como perspectiva característica do cronista, o olhar ao rés-do-chão (CANDIDO, 1984, p. 2-6). Em seus estudos sobre as cidades de São Paulo e Bogotá, Armando Silva propõe a noção de ponto de vista cidadão: "uma série de estratégias discursivas por meio das quais os cidadãos narram as histórias de sua cidade"(SILVA, 1997, p. 39). Em sintonia com essas propostas, as crônicas analisacias em minha pesquisa foram consideradas como estratégias discursivas que buscam incidir sobre as práticas cotidianas dos cidadãos. Ao mesmo tempo que aglutinam em torno de um sentimento comum (de prazer ou indignação) determinados grupos sociais, incidem crítica e incisivamente na realidade social. 
${ }^{5}$ A crônica, de acordo com Ramos, surgiu da fragmentação moderna, que mplicava "a experiência de uma temporalidade vertiginosa $\mathrm{e}$ fragmentária que anulava a possibilidade mesma de uma obra permanente".

(RAMOS, 1989, p.112)

\section{Instâncias precárias}

Mas é discreto o modo como a crônica entra no debate sobre a cidade. Entra pela via das páginas de entetenimento dos jornais e revistas. Entra no mesmo caderno onde estão o horóscopo, as palavras cruzadas, a coluna social e as tiras humorísticas. Dedicada aos pequenos e "intranscendentes" assuntos cotidianos, dedicada aos intersticios da vida diária, a crônica se oferece como uma espécie de arqueologia do presente (ROTKER, 1992, p. 21) Dessa forma, o cronista-arqueólogo nos apresenta uma cidade (e uns cidadãos) que, devido à proximidade e à familiaridade cotidiana, não vemos. Do mesmo modo que os achados arqueológicos revelam um passado daquilo que fomos, esta indagação do presente histórico dos cidadãos termina sendo um reflexo do que estamos sendo.

A crônica urbana - instância formalmente "precária" ${ }^{5}$ por excelência, move-se, portanto, pelo terreno do que Maffesoli chamou "pequenos nadas": esse conjunto de detalhes menores da vida diária que, apesar disso, criam um sistema significante. Destacando a relevância desses detalhes menores, dessas pequenas histórias da vida cotidiana, desses outros saberes, enfim, Maffesoli fala da "estreita conexão que existe entre as grandes obras da cultura e a "cultura" vivida diariamente"; essa "cultura" tecida pelo conjunto de "encruzilhadas, momentos, espaços e gente sem atributos; essa "cultura" que é feita de trivialidades" (MAFFESOLI, 1990, p. 56-57).

É precisamente sobre essas "trivialidades" que pousam os olhos do cronista. Reencontramos nesses textos aquilo que nos é familiar, o que - como habitantes da urbe - vivemos e praticamos cotidianamente. A crônica não revela, portanto, uma cidade desconhecida; ao contrário: nos devolve uma imagem que reconhecemos. Uma imagem algo deformada pelo processo de caricaturização operado pela crônica. Recorda, neste sentido, o espelho esperpêntico de Valle-Inclán, no qual a realidade se refletia deformada - artifício que permitia exercer uma crítica mordaz e incisiva da cultura.

Pois bem, se a crônica, concebida como espelho 
do que estamos sendo os cidadãos, se insinua como uma instância discursiva propositiva, que cidade se esboça naqueles textos? Que cidade imaginam, concebem os cronistas, que cidade propõem em seus textos?

Uma breve reflexão sobre as crônicas abordadas em minha pesquisa permitiu esboçar uma resposta possível: embora a cidade que se insinua naqueles textos não seja a concebida por Thomas Morus, a cidade proposta pelos cronistas se situa no que poderíamos chamar de $d i$ mensão utópica. Se o que reconhecemos naqueles textos é uma espécie de progressiva burocratização das relações, uma progressiva desumanização das relações entre os cidadãos, então é possível reconhecer também que subjaz nas crônicas um chamado à solidariedade, à ternura; subjaz uma aposta pelo humano.

E nesse sentido, considero oportuno recordar o que diz Arturo Andrés Roig a respeito da utopia:

A utopia é um lugar onde o viajante chega e onde encontra o que poderíamos considerar como a imagem invertida da própria cultura urbana do escritor que simula a viagem. E pode muito bem ocorrer que esse jogo de inversão seja realizado mediante um recurso que nos pinta não $o$ que a sociedade deveria ser, mas $\operatorname{sim}$ o que a sociedade $e ́$, mais matizada com uma pintura satírica. Deste modo, o 'não-lugar' [...] é na verdade 'o lugar', a topia sobre a qual se busca, mediante uma espécie de tiro parabólico, esboçar o dever ser social. (ROIG, 1999, p. 52)

A crônica apresenta-se, desse modo, como essa topia proposta por Roig: se oferece como um lugar que, a partir de uma "pintura satírica", reflete - para parafrasear Roig não o que deveríamos ser, mas, sim, o que estamos sendo. E ao fazê-lo, encerra e insinua um "dever ser". Situados nesta perspectiva, podemos ver como duas instâncias (o riso e a crônica) aparentemente "precárias" do ponto de vista do debate formal e acadêmico, se oferecem como um novo campo para o debate sobre a cidade e sobre os modos de ser dos cidadãos. 


\section{Referências}

ANDERSON, Benedict. Comunidades imaginadas. México:

Fondo de Cultura Económica, 1993.

BAHKTIN, M. La cultura popular en la Edad Media y en el

Renacimiento. Tradução Julio Forcat \& César Conroy.

Madrid: Alianza, 1990 [1965].

BARTHES, Roland. Semiología y urbanismo. In: La aventura semiológica. Barcelona: Paidós, 1993.

BERGSON, Henri. La risa. Ensayo sobre el significado de lo cómico. Buenos Aires: Losada, 1991.

BONFIM, Carlos. Humor y crónica urbana - ciudades vividas, ciudades imaginadas. Quito: Corporación Editora Nacional/UASB, 2003.

CANDIDO, Antônio. [et al.] A crônica: o gênero, sua fixação e suas transformações no Brasil. Campinas: UNICAMP; Rio de Janeiro: Fundação Casa de Rui Barbosa, 1992.

CERTEAU, Michel de. La invención de lo cotidiano I. Artes de hacer. Trad. Alejandro Pescador. México: Universidad Iberoamericana, 1996.

FREUD, Sigmund. El chiste y su relación con lo inconsciente. Madrid: Alianza, 1990.

MAFFESOLI, Michel. La comunidad emocional. In: E1 tiempo de las tribus: el declive del individualismo en las sociedades de masa. Barcelona: Icaria, 1990.

ORTEGA, Alicia. La ciudad y sus bibliotecas. El graffiti quiteño y la crónica costeña. Quito: UASB-Ecuador/ Corporación Editora Nacional, 1999.

PIRANDELLO, Luigi. El humorismo. In: Ensayos. Madrid: Guadarrama, 1968.

RAMOS, Julio. Decorar la ciudad: crónica y experiencia urbana. In: Desencuentros de la modernidad en América Latina: literatura y política en el siglo XIX. México: Fondo de Cultura Económica, 1989.

ROTKER, Susana. Fundación de una escritura. Las crónicas de José Martí. La Habana: Casa de las Américas, 1992. SILVA, Armando. Imaginarios urbanos. Cultura y 
comunicación urbana. Bogotá: Tercer Mundo Editores, 1997 [1992].

VILAS, Santiago. Hacia un concepto de humor. In: El humory la novela española contemporánea. Madrid: Guadarrama, 1968.

VIZCARRA, Fernando. Las ciudades nómadas: notas sobre comunicación y cultura urbana. In: Estudios sobre culturas contemporáneas. Colima/Mexico: 1996, v. II, n. 4. p. 83-93. 